\title{
Refractory Melanoma
}

National Cancer Institute

\section{Source}

National Cancer Institute. Refractory Melanoma. NCI Thesaurus. Code C147983.

Melanoma that does not respond to treatment. 